\title{
Da diversidade ao comum: práticas artísticas, cidadania e políticas sociais
}

\author{
De la diversidad al común: prácticas artísticas, ciudadanía y políticas \\ sociales
}

\author{
From diversity to the common: artistic practices, citizenship and \\ social policies
}

\author{
Ms. Isabela Umbuzeiro Valent ${ }^{1}$ \\ Dra. Eliane Dias de Castro ${ }^{2}$
}

\begin{abstract}
Resumo
Este trabalho aponta problematizações acerca de políticas relacionadas à diversidade, identidade cultural e cidadania, relacionando-as com situações localizadas em experiências artísticas que envolvem a participação de populações diagnosticadas por questões ligadas à saúde mental, vulnerabilidade social e deficiências, dentre outras condições desviantes. Destacam-se aspectos insistentes de formas coloniais, constituintes das relações de poder diante da atual incorporação de lógicas de mercado ao Estado, marcadas pelo neoliberalismo que afeta os processos de produção e realização artístico-culturais e a execução de políticas sociais. Esses processos desafiam a instauração de espaços comuns e de convivência e exigem experimentações para que deslocamentos se produzam. As situações apresentadas têm como característica o estabelecimento de comunidades que não se encaixam em definições identitárias, o que dificulta o acesso dessas populações às políticas culturais e de cidadania, já que se localizam nas fronteiras de certas identidades ou tem como critérios de agrupamento diagnósticos sociais e/ou de saúde. No entanto, são experiências que parecem trazer elementos que desafiam a lógica das políticas identitárias e a noção de identidade e diversidade cultural, pois instauram circunstâncias de desencaixe a esta lógica. Serão apontadas estratégias que vêm sendo implementadas por agentes que atuam neste no âmbito intersetorial desse campo, considerando os modos de produção da subjetividade contemporânea, a fim de discutir articulações entre ações estéticas e éticas relacionadas às políticas públicas atuais. ${ }^{3}$
\end{abstract}

Palavras-Chave: identidade; diversidade cultural; políticas culturais; diferença; práticas artísticas, políticas sociais.

\footnotetext{
${ }^{1}$ Doutoranda em Estética e História da Arte; Programa de Pós-graduação Interunidades em Estética e História da Arte da Universidade de São Paulo; São Paulo, SP, Brasil; isabelavalent@usp.br. Trabalho apresentado no I Seminário Latino-Americano de Estudos em Cultura - SEMLACult, Foz do Iguaçu/PR, Brasil, 2017. 2 Pós-doutorado em Educação e Teoria Geral da Arte na Universidade de Lisboa. Professora Doutora do Programa de Pós-graduação Interunidades em Estética e História da Arte da Universidade de São Paulo; São Paulo, SP, Brasil; elidca@usp.br

${ }^{3}$ Projeto financiado com apoio da Fundação de Amparo à Pesquisa do Estado de São Paulo (FAPESP), processo

n. 2016/17723-3
} 


\begin{abstract}
Resumen
Este trabajo apunta problematizaciones acerca de las políticas relacionadas a la diversidad, la identidad cultural y la ciudadanía, relacionándolas con situaciones presentes en experiencias artísticas que envuelven la participación de poblaciones diagnosticadas con problemas de salud mental, vulnerabilidad social y discapacidades, entre otras condiciones de desvío. Se destacan aspectos insistentes de formas coloniales constituyentes de las relaciones de poder y la actual incorporación de la lógica del mercado al Estado, marcadas por el neoliberalismo que afecta a los procesos de producción y realización artística y cultural y la ejecución de políticas sociales. Estos procesos desafían la creación de espacios comunes y de convivencia y exigen experimentos para que se produzcan desplazamientos. Las situaciones presentadas se caracterizan por la creación de comunidades que no se encajan en las definiciones de identidad, lo que dificulta el acceso de estas poblaciones a las políticas culturales y de ciudadanía, ya que se encuentran en las fronteras (o límites) de ciertas identidades o tienen como criterios de agrupación diagnósticos sociales y/o de salud. Sin embargo, son experiencias que parecen traer elementos que desafían la lógica de la política de la identidad y la noción de diversidad cultural, pues instauran circunstancias de desacoplamiento a esta lógica. Se identificarán estrategias que se han implementado por agentes que actúan en el ámbito intersectorial de este campo, teniendo en cuenta los modos de producción de la subjetividad contemporánea con el fin de discutir los vínculos entre las acciones estéticas y éticas relacionadas con las políticas públicas actuales.
\end{abstract}

Palabras claves: identidad, diversidad cultural, políticas culturales; diferencia; prácticas artísticas; políticas sociales.

\begin{abstract}
This work points to questions about policies related to diversity, cultural identity and citizenship, relating them to situations embedded in artistic experiences that involve the participation of populations diagnosed by issues related to mental health, social vulnerability and disabilities, among other deviant conditions. Emphasis is placed on colonial forms of power relations in the face of the current incorporation of market logic to the state, marked by the neoliberalism that affects the artistic-cultural production and realization processes and the implementation of social policies. These processes challenge the establishment of common spaces and coexistence and require experimentation for displacements to take place. The situations presented have as a characteristic the establishment of communities that do not fit into identity definitions, which makes it difficult for these populations to access cultural and citizenship policies, since they are located at the borders of certain identities or have the criteria of grouping social and / or health diagnostics. However, these are experiences that seem to bring elements that challenge the logic of identity politics and the notion of cultural identity and diversity, since they set up circumstances to undo this logic. Strategies that have been implemented by agents that work in this field will be pointed out in an intersetorial way, considering the forms of production of contemporary subjectivity in order to discuss articulations between aesthetic and ethical actions related to current public policies.
\end{abstract}

Keywords: identity; cultural diversity; cultural policies; difference; artistic practices; social policies. 


\section{Contextualização}

Este trabalho apresenta resultados parciais da discussão que vem sendo realizada na pesquisa de doutorado, em andamento, intitulada "Trajetórias em experiências com práticas artísticas na interface saúde e cultura em São Paulo: estratégias para a construção do comum”, que investiga um campo transdisciplinar de práticas que se dá nas interfaces entre as artes, a cultura e as políticas sociais - com destaque para as políticas de saúde - no município de São Paulo. A pesquisa parte da observação de trajetórias de vida de agentes que compõe este campo, evidenciando o caráter experimental e de agenciamento necessários para a construção de iniciativas transdisciplinares e intersetoriais. A partir de trânsitos entre credenciais de terapeuta ocupacional, produtor cultural, gestor do terceiro setor, militante, pesquisador, participante e artista, articula-se, em composição com outras pessoas ou entidades jurídicas, possibilidades de criação e sustentação de espaços de convívio entre pessoas de diferentes origens, gêneros, idades e condições de saúde ou sociais criando, mesmo que temporariamente, comunidades heterogêneas. Um dos principais desafios nesse percurso tem sido a formulação de estratégias para manter o aspecto inventivo e de resistência das ações, quando submetidas à procedimentos que garantam legitimação institucional, acesso a recursos e reconhecimento cultural e artístico. Muitos são os questionamentos que advém dessa imersão, entre eles destaca-se: como desenvolver estratégias de sustentação dessas práticas que também favoreçam rupturas ou subversões dos mecanismos hegemônicos de saber, poder e de produção de subjetividade, os quais parecem ser cruciais para a própria produção de isolamento e segregação social de populações em situações de vulnerabilidade?

Com o objetivo de conhecer e sistematizar diferentes estratégias de criação, articulação e participação nos processos de produção desses espaços comuns, focou-se, numa exploração inicial, na escuta e observação das ações e colaborações de agentes envolvidos nesse processo, seja a participação de um docente universitário que contribui para dar legitimidade à experiência como uma prática reconhecida e validada pelo discurso científico; de um sujeito diagnosticado com questões graves de sofrimento psíquico, mas que com sua singularidade ocupa os projetos dos grupos e contribui para novas direções das ações; de um estudante de graduação que constrói vínculos especiais com os projetos e participantes e, assim, sustenta espaços de escuta e sensibilidade para as diferenças; de um produtor/gestor que garante que o projeto receba recursos e esteja inscrito nos sistemas de cultura e arte; de um técnico de um serviço de saúde que acompanha e propicia a participação de sujeitos mais vulneráveis no grupo e tantos outros pequenos e complexos gestos de cada um que constroem 
esses agenciamentos coletivos. Assim, está sendo organizado um arquivo de depoimentos audiovisuais, com as histórias e relatos desses agentes, buscando cartografar as sutilezas de ações comuns em composição que efetivam práticas, políticas e modos de produção de cultura e de saúde, para além - e em relação com - projetos institucionais e programas implementados por políticas públicas sociais.

Os mapeamentos iniciais e as parcerias estabelecidas demonstram um grande número de projetos artístico-culturais, de pessoas atendidas e de profissionais envolvidos. São intervenções que exigem um conjunto de conhecimentos clínicos, críticos e políticos para o fortalecimento e duração das propostas; e ao mesmo tempo, acionam, no contato direto com as pessoas e grupos, uma força criativa que produz ideias, respostas, novas proposições, atendimentos singularizados, objetos artísticos, exposições, festas, encontros e eventos que criam um tecido vincular, vivo e pulsante, subjacente às normas sociais hegemônicas, no qual se inventa formas de partilhar a vida comum. Ações falam do trabalho de: acolher a diversidade e singularidade das demandas que emergem nas experiências e; auxiliar no enfrentamento das fragilidades e precariedades das situações de vida, saúde e cultura no espaço social. As transformações que vão se operando mostram a urgência dessa realização, enfatizam a reconstrução material e simbólica da vida e da subjetividade de grupos vulneráveis, e convocam participantes, profissionais, instâncias políticas, administrativas e gestores da cidade às prementes necessidades de intersecção e diálogo que reforcem as ações e projetos em suas diferenças. (CASTRO, 2016).

Essas experiências fornecem elementos para construir problematizações sobre as formas com que se dá a formulação de programas e ações que visam fortalecer a autonomia de grupos e de comunidades, evidenciando a importância de observar as necessidades singulares de cada território. É possível notar que, ao mesmo tempo em que fortalecem projetos, a existência de programas específicos para determinadas populações, tipos de produção cultural ou linguagens artísticas, pode também contribuir para a institucionalização de práticas, deixando pouco espaço para que novas formas de produção artística e de convivência encontrem possibilidades de existência. Assim, torna-se importante conhecer e refletir como se dão as experiências atuais por meio da ação de seus diferentes agentes, a fim de evidenciar a experimentação em dispositivos ${ }^{4}$ que possam inovar as formas de construir

\footnotetext{
${ }^{4}$ Compreende-se aqui a noção de dispositivo - que será melhor desenvolvido posteriormente, a partir da definição de Foucault (1995) como uma rede que se estabelece a partir da interação entre elementos heterogêneos, englobando discursos, instituições, organizações arquitetônicas, decisões regulamentares, leis, medidas administrativas, enunciados científicos, proposições filosóficas, morais, filantrópicas etc. Nesta
} 
estratégias para a efetivação de políticas intersetoriais ligadas a práticas culturais, que promovam aberturas a esse espaço comum, à cultura de qualquer um ${ }^{5}$.

\section{Apresentação do campo}

Este campo de práticas vem se constituindo há aproximadamente 20 anos como estratégias para promover a participação social e cultural de pessoas que, por múltiplas questões, vivem situações de vulnerabilidades e acabam tendo sua circulação restrita aos serviços de saúde e assistência social. São ações criadas para efetivar a implementação de um conjunto de políticas públicas sociais, que tem se intensificado no Brasil nos últimos anos, a partir da elaboração de legislações, programas e ações voltados à participação sociocultural e produção artística de populações em situações de vulnerabilidade, decorrentes de um novo cenário político e social.

No campo da saúde, o Movimento da Reforma Sanitária culminou na criação do Sistema Único de Saúde (SUS), modificando a compreensão de saúde, estabelecida como direito fundamental. As novas propostas compreendem a saúde de forma ampliada 6 , fortalecendo ações interdisciplinares que envolvem a vida cotidiana das comunidades. Destaca-se também, a organização das pessoas com deficiências que reivindica e assegura oportunidades de acesso aos potenciais criativos, artísticos e intelectuais para todos os cidadãos. O Movimento da Luta Antimanicomial e a Reforma Psiquiátrica, no âmbito da saúde mental, propuseram ações que visam garantir direitos fundamentais de pessoas com transtornos psíquicos, a partir de ações no território que implicaram estratégias de intervenção que envolvem a esfera social e cultural e necessitam, para sua efetivação, da integração dos usuários desses serviços em espaços socioculturais e comunitários. Práticas artísticas passaram a compor essas ações gerando possibilidades de troca com outras instituições e grupos artístico-culturais (CASTRO et al, 2016). O termo práticas artísticas é aqui utilizado

perspectiva, pretende-se observar como se dá o trânsito entre esses elementos na trajetória dos agentes estudados.

${ }^{5} \mathrm{O}$ conceito de qualquer é definido pelo ser em sua singularidade, não atrelado à sua identificação ou inclusão a uma determinada classificação ou classe; "considera-se que ele não remete para uma outra classe ou para a simples ausência genérica de pertença, seja ela qual for, mas para o seu ser-tal, para a própria pertença" (AGAMBEN, 1990, p. 12)

${ }^{6}$ A clínica ampliada é um conceito que vem sendo utilizado pelas políticas de humanização em saúde para compreender as ações de saúde para além do foco na doença, considerando os processos de adoecimento a partir de um olhar para o sujeito de forma singular. A perspectiva parte de uma implicação ética profunda e busca trabalhar de forma intersetorial em suas intervenções, reconhecendo os limites das práticas usualmente empregadas pelos profissionais de saúde, buscando integrar abordagens diversificadas e interdisciplinares que possibilitem o manejo da complexidade do trabalho em saúde. (BRASIL, 2009a; BRASIL, 2008) 
para designar atividades com finalidades fora de si mesmas, para além do objeto de arte e da sua construção (RIBEIRO, 2015). Essas finalidades parecem ser múltiplas, o que nos leva a perguntar como elas se articulam nas proposições instauradas por essa nova compreensão da produção de saúde?

Em um levantamento de práticas artísticas na interface da arte e da promoção da saúde na cidade de São Paulo, Castro e Silva $(2007)^{7}$ apontam que apenas $4 \%$ das propostas levantadas "atendem as demandas e interesses da população, configurando grupos heterogêneos e instaurando, a partir das atividades artísticas, uma nova consciência fundamentada no respeito aos direitos humanos e no acesso às produções culturais independentemente de categorias diagnósticas e de outras configurações da exclusão" (p. 107). No final dos anos 90, as demais práticas levantadas dirigiam-se exclusivamente a pessoas inseridas em diferentes categorias diagnósticas por critérios de saúde ou sociais. Cinquenta e um por cento das propostas atendiam pessoas com deficiência, 15\% consideravam a participação de pessoas com transtornos mentais, $11 \%$ compreendiam projetos específicos que utilizavam as artes no decorrer de tratamentos em saúde para alterações orgânicas e 19\% eram voltados especialmente para a população em risco social (CASTRO; SILVA, 2007). Esse quadro evidencia dificuldades de se implementar concretamente as políticas acima mencionadas, já que as práticas acabam ficando limitadas à populações específicas, reiterando diferenças em identidades segregadas e dificultando a convivência com o outro, em comunidades heterogêneas.

Neste cenário destaca-se a criação, em 1996, do Laboratório de Estudos e Pesquisa Arte, Corpo e Terapia Ocupacional ${ }^{8}$, que desenvolve ações de ensino, pesquisa e extensão universitária na interface das artes e da terapia ocupacional com a perspectiva de construir outros modos de cuidar de pessoas socialmente excluídas, despossuídas de suas redes de vida. Dentre essas, o Laboratório criou um projeto didático-assistencial em 1998, o Programa Composições Artísticas e Terapia Ocupacional (PACTO), que realiza práticas inovadoras, instaura referências nesse campo transdisciplinar e articula parceiros e projetos na produção de tecnologias socioculturais. São práticas de intervenção social com proposições criativas, artísticas e participativas para as populações atendidas, realizadas por meio de parcerias com

\footnotetext{
${ }^{7}$ A pesquisa realizou um levantamento ao longo de três anos (1999-2001) que localizou 193 propostas de atividades artísticas para populações em situação de vulnerabilidade e risco social localizadas na área cultural (97 propostas) e da saúde (96 propostas).

${ }^{8}$ O Laboratório é vinculado ao Curso de Terapia Ocupacional do Departamento de Fonoaudiologia, Fisioterapia e Terapia Ocupacional da Faculdade de Medicina da Universidade de São Paulo e credenciado como grupo de pesquisa do CNPq.
} 
projetos desenvolvidos em diferentes equipamentos da rede de saúde e cultura e iniciativas da sociedade civil. Assim, compõem um conjunto de ações diversas: ações educativas em museus; oficinas de artes e grupos culturais ligados a serviços de saúde mental, de atenção à população com deficiência e de assistência social; projetos autônomos que se constituíram na área da saúde e foram se emancipando em produções culturais independentes; além de outras propostas com inserções mais heterogêneas, como centros de convivência e centros de cultura, que acolhem e estimulam a participação de pessoas e comunidades em situações de vulnerabilidade. (CASTRO et al., 2016; COSTA et al., 2000; LIMA et al., 2009)

Desta forma, as atividades e articulações desenvolvidas pelo PACTO constituem uma rede de profissionais, estudantes e pesquisadores que têm buscado trabalhar na criação de ações que colaborem para resistir a dispositivos de patologização das diferenças, produzida pela restrição da circulação de pessoas com sofrimentos, deficiências ou situações de vulnerabilidade social a serviços de saúde e assistência por meio de agrupamentos baseados em diagnósticos. Assim, são atividades que têm como objetivo "produzir agenciamentos coletivos que não se pautem pela lógica da semelhança, mas que se fazem entre elementos heterogêneos" (LIMA, 2003, p. 28). É este tipo de agenciamento que denominamos como comunidades heterogêneas, ou seja, grupos e coletivos que se constituem a partir das diferenças e singularidades, integrando pessoas que, em muitas outras ocasiões, encontram-se segregadas. Adota-se o termo comunidade segundo a proposição de António Pinto Ribeiro (2015):

quando se nomeia uma comunidade deve-se, desde logo, acautelar-se contra a ideia de uma comunidade que é homogênea, com um passado comum e uma expectativa de futuro também ela comum em relação aos seus participantes. Ora, nada é mais contrário a esta constituição de uma comunidade do que esta falsa construção identitária. O que se deseja é que a comunidade se desenvolva a partir de uma diversidade interna, em que cada elemento tem múltiplas identidades, muitas delas em contradição. (RIBEIRO, 2015, p. 7)

Assim, as experiências desenvolvidas pelo PACTO envolvem inicialmente a prática da terapia ocupacional, mas atingem também os campos sociais e da saúde e instauram práticas culturais. Apesar de partirem de um campo disciplinar específico de atuação, colocam questões transversais que tocam aspectos sociais e políticos da convivência humana, mobilizando também a produção da subjetividade, os mecanismos de poder e seus modos de resistência na vida contemporânea. Dessa forma, exigem a articulação de diferentes áreas do conhecimento e contribuem para delinear analisadores de situações de sofrimento e exclusão 
nos processos de subjetivação contemporâneos. Suscitam assim, transversalidades entre temas como saúde mental, saúde coletiva, fundamentos e crítica das artes, práticas artísticas, filosofia, cultura, ciências sociais e educação, contribuindo para a ampliação e consistência de um campo em formação, e também, para o aumento de pessoas beneficiadas com as práticas de intervenção. Neste vasto movimento, intensifica-se, portanto, o desenvolvimento de estratégias para garantir o acesso às experiências culturais e artísticas do território da cidade e a promoção da convivência, o que abre para outras possibilidades como: a construção de projetos de vida; outras formas de participação e relacionamento interpessoal; acesso a redes de produção e emancipação cultural; estabelecimento de parcerias entre projetos e instituições que operam na interface arte, saúde e cultura e; discussão de estratégias e políticas intersetoriais para sustentar as proposições. (CASTRO et al, 2016b)

Como implementar, executar, sustentar e dar continuidade a esses tipos de prática? Que agenciamentos, proposições, projetos e marcas este território produz na experiência de vida das pessoas envolvidas e de que modo esses agenciamentos produzem esse próprio território? Como ativa novos modos de subjetivação? Que inovações engendra na convivência e na vida comum?

Para trabalhar essas questões está em desenvolvimento uma cartografia na qual vem sendo realizadas sistematizações de algumas estratégias atuais desse campo articuladas ao modo como vem sendo elaboradas e implementadas políticas sociais. Levantou-se também, conceitos analisadores, de forma a produzir perspectivas críticas acerca dessas estratégias, produzindo questionamentos que auxiliem a reconfiguração das forças constituintes desse campo comum e a formulação de propostas transdisciplinares e intersetoriais, apresentados a seguir.

\section{Problematizações}

Segundo Hölfing (2001), as políticas sociais determinam a forma de proteção social que o Estado implementa, tendo suas origens em movimentos do século XIX, relacionadas aos conflitos entre capital e trabalho e são, em princípio, voltadas para a "redistribuição dos benefícios sociais visando a diminuição das desigualdades estruturais produzidas pelo desenvolvimento socioeconômico”. A autora compreende políticas públicas como aquelas de responsabilidade do Estado, quanto à implementação e manutenção a partir de um processo de tomada de decisões que envolve órgãos públicos e diferentes organismos e agentes da 
sociedade relacionados à política implementada. Neste sentido, políticas públicas não podem ser reduzidas a políticas estatais. (HÖFLING, 2001, p. 31)

Dardot e Laval (2016) apontam que, diferentemente do funcionamento da noção de ausência do Estado no liberalismo, o neoliberalismo incorpora a lógica de concorrência ao funcionamento do Estado, internalizando seus mecanismos e moldando a conduta dos governantes e governados. Essa racionalidade opera no sentido de obstruir relações de solidariedade, instaurando a competição entre sujeitos, regiões e nações. O procedimento consiste em fazer com que os indivíduos concorram entre si, gerando um endividamento crônico diante de um modelo de produtividade segundo a lógica das empresas. Esses mecanismos geram um indivíduo competente e competitivo que se torna responsável ele mesmo pelo seu próprio empreendimento, já que abolem-se cada vez mais as relações explícitas de sujeição e dominação pela lógica do contrato de trabalho (DARDOT; LAVAL, 2016). Assim, o neoliberalismo produz, em seu aspecto social, a individualização das relações por meio de uma racionalidade normativa generalizada que opera o poder de forma capilar.

Dessa forma, é importante refletir sobre como se dá a compreensão e a participação da sociedade nas políticas públicas sociais neste contexto onde prevalece a concepção neoliberal. Qual a percepção do lugar e do papel do Estado na relação que os sujeitos estabelecem com ele - e entre si - acerca das questões sociais da vida comum e cotidiana?

Em um Estado de inspiração neoliberal as ações e estratégias sociais governamentais incidem essencialmente em políticas compensatórias, em programas focalizados, voltados àqueles que, em função de sua "capacidade e escolhas individuais", não usufruem do progresso social. Tais ações não têm o poder de -e frequentemente, não se propõem a-alterar as relações estabelecidas na sociedade. (HÖFLING, 2001, p. 39)

Essa perspectiva compensatória contribui para um efeito normativo e apaziguador das políticas sociais, na medida em que personalizam problemas e necessidades às referidas populações mais vulneráveis, atribuindo inclusive essa vulnerabilidade a aspectos individuais e de responsabilidade exclusiva do próprio indivíduo. Dessa maneira, a resposta do poder público para resolver questões como: o sofrimento psíquico; as desvantagens para a participação social da pessoa com deficiência; as complexas situações sociais de sujeitos que não encontram formas de se inserir no mercado de trabalho capitalista e moram nas ruas; a situações de precariedade para acesso à moradia, aos fenômenos sociais relacionados ao uso problemático de drogas em locais degradados da cidade; dentre outras - parece se dar, quase que exclusivamente, com programas e projetos pontuais que oferecem serviços direcionados a esses indivíduos, categorizados em populações específicas. Essa forma de lidar com os 
problemas prejudica a compreensão dos mesmos como questões comuns. $\mathrm{O}$ atendimento quase literal aos pedidos e demandas - supostamente entendidos como necessidades dessas populações - faz calar vozes singulares, que personificadas como apenas desses sujeitos, apaziguam diferenças contidas nas situações de desvio, abafando possibilidades de escolha e da compreensão dessas questões como coletivas.

O mecanismo de individualização é evidenciado na constatação do surgimento de políticas de reconhecimento de pessoas e populações a partir de suas marcas identitárias. Diante da perspectiva crítica instaurada pela noção da biopolítica enquanto regime de poder hegemônico (FOUCAULT, [1976] 1997), pode-se localizar neste movimento riscos de categorizar sujeitos e populações homogeneizando diferenças ao instaurar modelos normativos do comportamento e da subjetividade, que acabam sendo entendidos numa noção essencialista do sujeito, ao invés de compreendidos como um processo de subjetivação que produz, a partir das singularidades e da diferenciação, novos modos de existência continuamente.

\footnotetext{
"Esta forma de poder aplica-se à vida cotidiana imediata que categoriza o indivíduo, marca-o com sua própria individualidade, liga-o à sua própria identidade, impõe-lhe uma lei e verdade, que devemos reconhecer e que os outros têm que reconhecer nele. É uma forma de poder que faz dos indivíduos sujeitos. Há dois significados para a palavra sujeito: sujeito a alguém pelo controle e dependência, e preso à sua própria identidade por uma consciência ou autoconhecimento. Ambos sugerem uma forma de poder que subjuga e torna sujeito a." (FOUCAULT, 1995, p. 235)
}

Duarte et al (1993) salientam que, ao longo do séc. XIX surgem as primeiras políticas públicas voltadas para a construção de cidadania e não apenas à consolidação do Estado. Essas políticas, embora possibilitem maior acesso à educação letrada e cívica, à saúde, à previdência social e à experiência política - veículos para a cidadanização - também operam para a reprodução de ordens de discriminação dos sujeitos sociais perante o Estado. Para os autores, pode-se traçar um paralelo entre os processos de cidadanização e a biopolítica, proposta por Foucault. A cidadanização contribui assim, para a constituição de uma rede de controle dos sujeitos em um processo indissociável do individualismo ou da individualização. (DUARTE et al., 1993)

Holfing (2001) propõe que, mais do que oferecer "serviços" as ações públicas, articuladas com as demandas da sociedade, devem se voltar para a construção de direitos sociais (p. 40). Porém, na interpretação e regulamentação de políticas públicas é possível notar uma tendência de transformar direitos sociais em direitos específicos de sujeitos ou grupos populacionais, dirigidos àqueles mais vulneráveis justamente pela ausência de direitos sociais. Pode-se observar, no campo das políticas públicas de cultura, a crescente 
implementação de programas e ações que tem como objetivo favorecer o desenvolvimento ou de promover a inclusão - de populações específicas, muitas vezes definidas a partir de categorias sociológicas, étnicas, raciais ou territoriais. Esse funcionamento pode ser observado na regulamentação e implementação da Lei Cultura Viva (2014), que determina como beneficiária

a sociedade e prioritariamente os povos, grupos, comunidades e populações em situação de vulnerabilidade social e com reduzido acesso aos meios de produção, registro, fruição e difusão cultural, que requeiram maior reconhecimento de seus direitos humanos, sociais e culturais ou no caso em que estiver caracterizada ameaça a sua identidade cultural (BRASIL, 2014)

Apesar da definição da população, no texto, ser geral e não se basear em categorias identitárias, nota-se que a implementação dessa política pública tem se dado por meio da nomeação de populações específicas. Este aspecto pôde ser notado através da observação dos critérios de seleção e participação do Programa Cultura Viva, adotadas pelos estados e municípios, bem como pela forma com que tem se dado a organização, representação e agenciamento dos beneficiários e agentes dessa política. Em diferentes âmbitos - nacionais, estaduais e municipais - tem-se praticado formas de organização em comissões e fóruns, que adotam como categorias de participação e representação grupos temáticos a partir de identidades culturais específicas, para além das representatividades territoriais, como por exemplo: matrizes africanas, gênero, hip-hop, juventude, criança e adolescente, grupo amazônico, comunidades tradicionais, LGBT, ribeirinhos, matrizes indígenas, artes visuais, capoeira ${ }^{9}$. É importante observar que essas categorias são estabelecidas a partir da própria enunciação dos participantes, que vão se agrupando a partir de elementos similares, instaurando grupos específicos. É interessante notar que os grupos adotam critérios diferentes entre si para essa identificação: alguns se baseiam em características de formas de vida; outros em linguagens artísticas ou, ainda; origens étnicas, raciais, sociais ou de gênero; dentre outras.

São iniciativas destinadas a populações nomeadas como minoritárias, numa lógica de pertencimento social funciona e se estrutura a partir de categorias identitárias, reiterando, mesmo que numa plausível iniciativa de proteção ou restauro de culturas, uma posição que cria a própria cisão e a hierarquização de diferentes formas de vida e subjetividades. Iniciativas que operam a partir de uma visão da identidade alijada de seus processos de produção e da diferença (DA SILVA, 2000).

\footnotetext{
${ }^{9}$ As categorias descritas remetem aos grupos de trabalho que compuseram a Comissão Nacional dos Pontos de Cultura (CNPdC), composta pela sociedade civil na gestão de 2011, publicada na página virtual da CNPdC, http://pontosdeculturabrasil.redelivre.org.br/a-comissao/representantes/ (acesso em 29/07/2017).
} 
Nesse tipo de proposição, a noção de diversidade cultural parece se dar como um rol variado de identidades específicas, personalizando o acesso à cultura e o exercício da cidadania cultural a grupos, comunidades ou populações com características similares, de afinidade ou conformidade. Esse processo estimula a competição entre as diferentes minorias de modo a acirrar operações de concorrência e segregação entre elas. Se essas iniciativas passam a reconhecer - e dessa forma, promover acesso à cidadania de pessoas antes marginalizadas, elas permanecem não reconhecendo como parte da diversidade cultural todos aqueles que não se encaixam numa identidade definida de forma afirmativa. Este ponto tornase especialmente delicado quando nos referimos a populações desviantes, muitas vezes invisíveis, oprimidas, encarceradas, abandonadas ou rejeitadas: pessoas em situação de rua, usuários de serviços de saúde mental, pessoas com deficiências ou em privação de liberdade. Essas denominações constituem populações demarcadas por faltas ou desvios a um padrão normativo e essencialista. São pessoas que parecem só serem reconhecidas por marcas vinculadas a faltas ou inadequações, ou seja, um reconhecimento que se dá a partir daquilo que não se é - ou se deveria ser. Existências declaradas a partir do déficit, da negatividade, do avesso, do resto.

É possível assim, observar um uso da noção de culturas enquanto formas de vida para um projeto civilizatório dessas minorias. Essa dinâmica evidencia rastros de uma lógica colonizadora, na medida em que pode ser usada para exercer o controle sobre esse outro minoritário ou subalterno. Gayatri Spivak ([1985] 2010) provoca essa questão insistindo que “o sujeito subalterno colonizado é irremediavelmente heterogêneo” (SPIVAK, 2010, p. 57). Para a autora, as classes subalternas têm sua identidade na diferença, afirmando que o termo subalterno não pode ser utilizado para se referir a todo sujeito marginalizado. Resgata seu significado no sentido do aspecto daquele cuja voz não pode ser ouvida, constituindo camadas mais baixas da sociedade, excluídas da possibilidade de se tornarem parte do estrato social dominante (SPIVAK, 2010, p. $5^{10}$ ). As classes subalternas são compostas pelo resto ou sobra da equação entre aqueles enquadrados em estratos sociais dominantes - no caso, o mecanismo de dominação se dando a partir da classificação identitária - e todos os outros que não compõem esse grupo. Essas populações, denominadas em sua negatividade, apontam para algo que caduca neste mecanismo de categorização e, dessa forma, parece ser oportuno nos debruçarmos sobre esses agrupamentos de pessoas, observando possíveis linhas de fuga e apostando que possam apontar outros paradigmas para a produção do comum.

\footnotetext{
${ }^{10}$ prefácio de Sandra Regina Goulart Almeida
} 
Podemos observar uma experiência pontual de construção de políticas públicas na interface entre saúde mental e cultura que se deu entre os anos de 2007 e 2009 . A publicação Loucos pela Diversidade: da diversidade da loucura à identidade da cultura (AMARANTE; LIMA, 2008) reúne a sistematização de uma Oficina Nacional de Indicação de Políticas Públicas Culturais para pessoas em sofrimento mental e em situações de risco social e apresenta algumas pistas para o debate. A iniciativa reuniu diferentes projetos participantes, nos quais é interessante notar a presença da utilização de nomeações que se definem atreladas à ideia da loucura. Destacam-se os projetos apresentados no evento que se utilizam dessa estratégia: Lokomotiva; Pirei na Cena; TV TAM TAM; Loucos pela Vida; TV Parabolinóica; Antena Virada; Bicho de sete cabeças; Loko na Boa; Harmonia Enloquece e TV Pinel.

Outro mecanismo se configura em situações criadas quando essa localização se dá por meio de nominações como usuários de serviços de saúde mental, por exemplo, tentando, de alguma maneira, endereçar essa categorização à localização da posição social em que esse sujeito está colocado e não à sua identidade. Em 2009, a iniciativa Prêmio Loucos pela Diversidade 3, concurso público nacional, que objetivava fortalecer e dar visibilidade a práticas artísticas realizadas por grupos, organizações ou instituições ligadas à saúde mental, se utiliza dessa estratégia, destinando como público alvo do prêmio usuários de serviços de saúde mental. O edital previa como objetivos do prêmio a construção de um país mais democrático, no sentido de promover a todos o direito à criação e a produção cultural; o protagonismo de pessoas em sofrimento psíquico; a visibilidade de trabalhos que propõe a emancipação e autonomia através de iniciativas de cunho artístico e cultural e, a promoção da interação desses grupos com a sociedade em geral. (BRASIL, 2009b)

Mas, esse movimento, embora permita o acesso à recursos para a produção, criação e circulação cultural, enquadra os projetos em rubricas que podem acabar por reiterar o estigma e a própria lógica que produz a exclusão dos sujeitos que dele participam. Comumente, os grupos artísticos oriundos de serviços sociais ou de saúde mental tem sua circulação nos circuitos artístico-culturais muito restritas. Quando suas obras circulam, o reconhecimento parece se dar pouco pelo que de fato é exibido ao público, já que, ao enunciarem-se como um projeto ligado à saúde mental ou prática social. Muitas vezes a visibilidade de sua produção encerra-se na rubrica da arte exótica do "louco" ou da sobreposição do olhar benevolente do público à essa população em detrimento à dimensão estética da recepção do que lhe é apresentado. Corre-se, assim, o risco de restringir referências para a construção de outras chaves de reconhecimento desses sujeitos - além da condição de desvio, na medida em que este internaliza essa identidade em sobreposição a outras possíveis. Incentivar o 
fortalecimento desta única possibilidade identitária como o viés das políticas afirmativas propõe, em seu princípio de discriminação positiva, parece não funcionar tão bem nesses casos.

Foucault (2004), em uma entrevista onde comenta pontos acerca do dispositivo da sexualidade, do poder e das políticas de identidade ${ }^{11}$ aponta que, diante das relações de poder estamos em uma luta, em uma relação estratégica uns em relação aos outros, reiterando o caráter de jogo para que possamos criar formas de atuar nos interstícios dos dispositivos. Acerca da identidade ele afirma:

\begin{abstract}
se a identidade é apenas um jogo, apenas um procedimento para favorecer relações, relações sociais e as relações de prazer sexual que criem novas amizades, então ela é útil. Mas se a identidade se torna o problema mais importante da existência sexual, se as pessoas pensam que elas devem "desvendar" sua "identidade própria” e que esta identidade deva tornar-se a lei, o princípio, o código de sua existência, se a questão que se coloca continuamente é: "Isso está de acordo com minha identidade?", então eu penso que fizeram um retorno a uma forma de ética muito próxima à da heterossexualidade tradicional. Se devemos nos posicionar em relação à questão da identidade, temos que partir do fato de que somos seres únicos. Mas as relações que devemos estabelecer conosco mesmos não são relações de identidade, elas devem ser antes relações de diferenciação, de criação, de inovação. É muito chato ser sempre o mesmo. Nós não devemos excluir a identidade se é pelo viés da identidade que as pessoas encontram seu prazer, mas não devemos considerar essa identidade como uma regra ética universal. (FOUCAULT, 2004, p. 265-266)
\end{abstract}

Nesse jogo, segundo o autor, “devemos não somente nos defender, mas também nos afirmar, e nos afirmar não somente enquanto identidades, mas enquanto força criativa" (FOUCAULT, 2004, p. 262). Podemos talvez aproximar essa força criativa pela afirmação das práticas artísticas, para criar outras estratégias além de recusar qualquer definição identitária de um sujeito individual ou coletivo, mas operando a partir da própria lógica desses dispositivos. Ele afirma: "não estou seguro de que nós devamos criar nossa própria cultura. Nós devemos criar uma cultura. Devemos realizar criações culturais.”. (Ibid., p. 262)

Ao invés então do fortalecimento de identidades, outra possível aposta é a de criar condições para que as pessoas em situações estigmatizantes se apropriem de nomeações diversas, num jogo de travestimentos e/ou a partir de associações com outros sujeitos com maior contratualidade, de forma a utilizar passaportes transitórios, criando movimentos para atravessar fronteiras. Porém esse jogo é complexo e cheio de armadilhas. Diante da crítica da concepção de um sujeito coletivo monolítico, uma das alternativas, trabalhada por Spivak ([1985] 2010), é a de um uso estratégico dos essencialismos, mantendo em problematização

\footnotetext{
${ }^{11}$ Apesar do autor trabalhar a produção de identidade no âmbito da sexualidade, a reflexão parece também oportuna à temática aqui desenvolvida.
} 
constante o risco positivista de que uma afirmação identitária revelaria a verdade ou a consciência de um sujeito ou classe. Segundo Carvalho (2011), comentando a obra de Spivak:

\begin{abstract}
"a cultura não pode ser tida por uma instância monolítica ou estanque que determinaria as ações ou um sujeito. Assim, a autora enfatiza que se devemos trabalhar com categorias que refletem movimentos abrangentes este deve ser caracterizado pela heterogeneidade. Daí a importância do intelectual não falar no lugar do subalterno, dado que tal ação sempre tende a pressupor uma essência a ser articulada pelo discurso especializado" (CARVALHO, 2001, p. 65-66)
\end{abstract}

Artistas, pesquisadores, gestores, técnicos de saúde e de assistência social, bem como os próprios movimentos sociais desses grupos precisam estar atentos ao utilizar o essencialismo de forma estratégica pois, ao falar pelos sujeitos que não podem falar, corre-se o risco de protagonizar uma nova missão colonial através de sua representação. A autora propõe a utilização do termo representação em dois sentidos distintos: o sentido de falar por e o sentido do termo enquanto encenação. Nessa distinção podemos localizar algumas alternativas diante da condição de dificuldade para a realização de agenciamentos individuais e coletivos do subalterno. Uma delas é a permanente diferenciação entre a representação do subalterno como uma encenação estratégica da representação enquanto a tomada de consciência de um sujeito coletivo, já que, para Spivak, a representação do oprimido, por trás de um verniz libertário, pode acabar por ajudar na manutenção de práticas essencialistas e imperialistas que resultam em violência epistêmica cotidiana. (CARVALHO, 2011, p. 66)

A partir dessas reflexões, é possível pensar que este funcionamento que tende à individualização não está, em sua totalidade, localizado na elaboração em si das leis e regulamentação dos programas. Ele também se dá pelos modos como são organizadas suas efetivas ações pelos gestores e sociedade civil, agentes dessas políticas, evidenciando a necessidade de intervenções em aspectos ligados à produção de subjetividade, para a garantia das diretrizes previstas nas formulações de políticas públicas. Estes são desafios que exigem intervenções sutis nos dispositivos, definidos por Foucault (1995) como relações de uma rede que se estabelece a partir da interação entre elementos heterogêneos, englobando discursos, instituições, organizações arquitetônicas, decisões regulamentares, leis, medidas administrativas, enunciados científicos, proposições filosóficas, morais, filantrópicas etc. Para o autor, o dispositivo se constitui a partir relação que se pode estabelecer entre esses elementos. Ele afirma que uma das razões da força do poder do Estado é seu caráter tanto individualizante quanto totalizador, capaz de ampliar o poder através do corpo social em múltiplas instituições como a família, a medicina, a psiquiatria, a educação, dentre outras, concluindo que: 
“o problema político, ético, social e filosófico de nossos dias não consiste em tentar liberar o indivíduo do Estado nem das instituições do Estado, porém nos liberarmos tanto do Estado quanto do tipo de individualização que a ele se liga. Temos que promover novas formas de subjetividade através da recusa deste tipo de individualidade que nos foi imposto há vários anos." (FOUCAULT, 2004, p. 239)

\section{Deslocamentos e práticas artísticas}

Diferentemente das práticas artísticas com motivações políticas que aproximavam arte e vida das décadas de 1960 e 1970, a esfera política em algumas práticas de arte contemporânea se dá a partir de jogos que mobilizam forças no campo social, no qual a tática do artista proporciona certas fissuras entre o que se compreende como arte e não arte, evitando qualquer prévia determinação e embaralhando identidades. No constante deslocamento entre os espaços artísticos instituídos e o campo social, manifestações estéticas surgem dentro e fora do sistema da arte, voltando-se para o campo da cultura, envolvendo outras instituições, subjetividades e comunidades. Estes artistas - legitimados pelo sistema da arte - embaralham-se em ações ativistas, etnográficas, pedagógicas, assistenciais, terapêuticas e políticas que, em alguns momentos podem correr o risco de tomar a arte enquanto ferramenta para a promoção de cuidado, saúde ou inclusão social (FABBRINI, 2010). Nessas práticas, a colaboração e participação das pessoas envolvidas pode se dar de múltiplas maneiras. A variedade de abordagens, formas de trabalho e modos de circulação e exibição das práticas nos levam a perguntar quais são seus efeitos na produção do comum.

Nesse emaranhando de experimentações, artistas saem de espaços tradicionalmente destinados à arte, colocando em cena ações que transgridem e põem em cheque convenções e limites de definiçãa de valor e qualidade da arte. Ações, que, se realizadas por pessoas que não possuem essa credencial - legitimada pela identidade de artista reconhecido pelas instituições e sistema de arte - teriam muito mais chances de serem reprimidas por forças policiais e mantenedoras da ordem social na trama da cidade. Assim, sob a proteção dessa credencial, as ações artísticas ganham possibilidade de existência e reverberações, mas também tem sua potência um tanto apaziguada na medida em que o público percebe que se trata de uma performance artística. Dessa forma, não se trata de transformar pessoas enquadradas em diagnósticos de saúde ou sociais em artistas, mas experimentar espécies de travestimentos transitórios, que permitam circulações inusitadas, atentos para seus possíveis deslocamentos, diluindo fronteiras e colocando em evidência limitações e possibilidades de uma nova participação sociocultural. Assim, o que parece estar em jogo no envolvimento 
dessas populações em projetos artísticos colaborativos é a possibilidade de gerar trânsitos. Esses deslocamentos são permitidos pela credencial obtida a partir da participação em ações que se enunciam como arte nos dias atuais. Já que essa autorização depende da legitimação do sistema da arte, coloca-se como questão a responsabilidade daqueles que empreendem um projeto artístico com essas pessoas frente aos desdobramentos possíveis desse jogo de fronteiras, da acentuação crítica das proposições, no estabelecimento de aproximações e distanciamentos e do reconhecimento das realidades contraditórias.

No ensaio $O$ artista enquanto etnógrafo, o pesquisador e crítico Hal Foster (2005) aponta alguns perigos das práticas de arte contemporânea que se constroem a partir do contato do artista com um outro definido em termos antropológicos, culturais ou étnicos. A partir de um paralelo com o texto "O autor como produtor" de Walter Benjamin ([1934] 2012), Foster sugere a ideia do artista enquanto etnógrafo. Se em Benjamin a relação do sujeito com seu outro é definida por uma relação econômica, em Foster esse outro é demarcado a partir de sua identidade cultural. Algumas pressuposições já presentes no texto de Benjamin configuram o que Foster identifica como o risco de um patronato ideológico, que permanecem no paradigma do artista enquanto etnógrafo: (1) o lugar da transformação política é o mesmo da transformação artística; (2) este lugar de transformação é sempre um lugar no campo do outro - colonial, subalterno, subcultural ou oprimido pós-colonial - onde a cultura dominante será subvertida; (3) se o artista não for percebido como esse outro, ele terá acesso limitado a esta alteridade transformadora. $\mathrm{O}$ centro desse perigo tem origem no risco da cisão presumida entre o artista e esse outro, mas também na própria identificação utilizada para superar essa cisão (FOSTER, 2005).

A inserção dessas produções no campo específico da arte, a partir da associação com artistas e a ocupação de circuitos artísticos legitimados e reconhecidos no campo da cultura, fora das rubricas nomeadas anteriormente parece ser outra estratégia, evitando utilizar a arte nesses contextos como um recurso para inclusão, para a cura, para o cuidado, ou a favor do que quer que seja que não seja a própria criação artística.

Um exemplo interessante desse jogo é a experiência da Cia Teatral UEINZZ, um grupo de teatro composto por atores com transtornos psíquicos e terapeutas com sede em São Paulo, e em cena há aproximadamente 20 anos, que se destaca por transitar nos circuitos da arte, não dependendo de espaços exclusivos a estes grupos especiais. Ao observar sua trajetória, percebe-se que grande parte dessa circulação é permitida pela presença de alguns integrantes do grupo que parecem emprestar suas credenciais individuais: um filósofo reconhecido no campo intelectual e artístico abre passagens para que o grupo tenha espaço em 
programações culturais; a parceria com uma artista reconhecida leva o grupo à um dos maiores eventos de arte contemporânea internacional e assim por diante. De certa forma, o lugar legitimado do artista ou intelectual funciona como uma espécie de agente alfandegário que permite trânsitos improváveis sem esta mediação. Isso nos dá pistas acerca da questão da responsabilidade do artista que propõe experiências artísticas com esses outros. Também, o participante dito "louco" deste grupo pode funcionar como agente alfandegário, permitindo ao público e aos demais participantes o trânsito por lugares que escapam ao normativo e o acesso a linhas de fuga que, comumente perderiam força - para esses sujeitos e todos nós - ao encerrarem-se na rubrica da doença.

\section{Considerações finais}

Fabbrini (2010) chama nossa atenção para questões que problematizam os modos com que se realizam as produções artísticas colaborativas. Um dos problemas levantados pelo autor diz respeito às implicações políticas dessa forma de fazer arte. Será que, em alguns momentos, elas podem funcionar como tentativas de reparação, confundidas com ações conciliatórias, que tendem ao consenso, instaurando espaços de convívio que intencionam recuperar uma idealizada experiência comunitária perdida? Essas indagações nos levam a pensar se, mesmo numa arte que se pretende política ou numa cultura que se pretenda cidadã, pode-se correr o risco de reproduzir uma lógica assistencialista ou que reitera uma condição hierarquizada, desvanecendo assim efeitos políticos de emancipação de pessoas e comunidades.

Em contraposição à ideia consensual de inclusão social, propõe-se efeitos de emancipação que, de acordo com Rancière (2012), não são a saída de um estado de minoridade, mas se instauram na possibilidade do deslocamento entre aqueles que podem e não podem falar, na "igualdade da inteligência em todas as suas manifestações" (ibid., p. 20). Mas, quais elementos presentes nessas práticas podem desafiar esse desejo nostálgico de uma comunidade perdida, já que a conciliação e o consenso não são o efeito político esperado de uma prática artística? Ao contrário disso, como instaurar as possibilidades de surgirem dissensos, uma vez que "o dissenso põe em jogo, ao mesmo tempo, a evidência do que é percebido, pensável e factível e a divisão daqueles que são capazes de perceber, pensar e modificar as coordenadas do mundo comum” (ibid., p. 49), gerando assim, efeitos políticos, já que reconfiguram efetivamente os modos de relação entre uns e outros?

O conceito de comum, formulado por Hardt e Negri (2005), se pauta na perspectiva da 
multidão, de uma produção subjetiva que se dá pelas singularidades em cooperação, sem se constituir como uma unidade ou um sujeito coletivo único. Seria o espaço de uma democracia absoluta, na produção de um governo de todos por todos. Podemos aproximar a noção de comum ao que Rancière (2005) propõe como uma política do anônimo, que ressalte a voz de qualquer um, daqueles que não têm direito de falar ou de se expressar em outras linguagens Outros autores contemporâneos como Jean-Luc Nancy (1986, 2001); Giorgio Agamben (1990) e; Maurice Blanchot (1986) têm proposto denominações que discutem as noções de comunidade e que podem ser aproximadas à noção de política do anônimo. São definições de formas de vida que escapam à ideia de comunidade fusional ou identitária: comunidade dos celibatários; comunidade negativa; comunidades dos sem comunidade; a comunidade possível; a comunidade de jogo; a comunidade que vem; a comunidade da singularidade qualquer (PÈLBART, 2008).

Essas outras formas de compreender a comunidade e o comum podem ser caminhos conceituais para repensar o termo diversidade cultural a partir da perspectiva da produção de subjetividade e instaurar práticas em interface que sustentem as novas composições em operação. A convivência e as trocas micropolíticas engendradas entre todos os participantes dos acontecimentos artísticos operam a produção de coletivos resistentes na constante reinvenção dos modos de se relacionar e de viver. Instauram, na cultura dominante, exercícios estéticos que transformam a existência na cidade, e aferem uma reformulação da percepção do outro e do mundo num compartilhamento sensível comum; o que também pressupõe aprendizados de relação com a diferença em muitos planos: de estar junto, de vivência das práticas, de construções transversais, de distribuição do saber e do poder.

São problematizações que abrem muitos questionamentos: como efetivar políticas sociais que possam acolher existências singulares, sem tê-las que definir a partir de uma identidade? É possível promover políticas públicas que favoreçam a coexistência de subjetividades diversas, múltiplas e singulares? Como pensar a cultura a partir da multiplicidade e do dissenso, em contraposição ao consenso da diversidade de culturas específicas? Que tipo de ações podem contribuir para a construção dos direitos sociais? Como interferir nos processos de produção de subjetividade, a partir de políticas públicas, de modo a deslocar esse excessivo foco no indivíduo para a dimensão social e coletiva da vida em comum? 


\section{Referências Bibliográficas}

AGAMBEN, G. A comunidade que vem. Lisboa: Editorial Presença, 1990.

AMARANTE, P. D. C.; LIMA, R. (Coord). Loucos pela diversidade: da diversidade da loucura à identidade da cultura. Relatório Final da Oficina Nacional de Indicação de Políticas Públicas Culturais para Pessoas em Sofrimento Mental e em Situações de Risco Social. Rio de Janeiro, 2008.

BENJAMIN, W. [1934]. O autor como produtor. In: Magia e Técnica, Arte e Política: ensaios sobre literatura e história da cultura. São Paulo: Editora Brasiliense, 2012.

BLANCHOT, M. La communauté inavouable. Paris: Minuit, 1986.

BRASIL. Clínica ampliada, equipe de referência e projeto terapêutico singular / Ministério da Saúde, Secretaria de Atenção à Saúde, Núcleo Técnico da Política Nacional de Humanização - 2. ed. - Brasília: Ministério da Saúde, 2008.

BRASIL. Política Nacional de Humanização da Atenção e Gestão do SUS. Clínica ampliada e compartilhada / Ministério da Saúde, Secretaria de Atenção à Saúde, Política Nacional de Humanização da Atenção e Gestão do SUS. - Brasília: Ministério da Saúde, 2009a.

BRASIL. Edital n. 001, de 20 de maio de 2009 - Concurso Público Prêmio Cutlural Loucos pela Diversidade 2009. Ministério da Saúde; Ministério da Cultura, 2009b. Disponível em: <http://www.cultura.gov.br/documents/10883/38605/edital_procuradoria_25maio1.pdf/fef5fa 74-0f64-44c9-9079-2bd8d7f12657>. Acesso em: 9 nov. 2015

BRASIL. Lei n. 13.018, de 22 julho de 2014. Brasil, 2014.

CARVALHO, B. S. DE. Subalternidade e possibilidades de agência: uma crítica pósColonialista. Revista Estudos Políticos, n. 3, p. 65-69, 2011.

CNPdC. Representantes da Comissão Nacional dos Pontos de Cultura - gestão 2011 http://pontosdeculturabrasil.redelivre.org.br/a-comissao/representantes/. Acesso em: 29/07/2017.

CASTRO, E.D. A construção dos direitos, o papel e o trabalho da universidade. Fala para a Mesa da Audiência Pública: Câmara Municipal de São Paulo, 16 de novembro de 2016a. Comissão de Saúde, Promoção Social, Trabalho e Mulher. Comissão de Educação, Cultura e Esportes. Disponível em: http://camarasp.flashserverbr.com/23547. Acesso em: 31 jul. 2017

CASTRO, E. D. et al. Território e diversidade: trajetórias da terapia ocupacional em experiências de arte e cultura. Cadernos de Terapia Ocupacional da UFSCAR. São Carlos, v. 24, n. 1, p. 3-12, 2016.

CASTRO, E. D.; SILVA, D. D. M. Atos e fatos de cultura: território das práticas, interdisciplinaridade e as ações na interface da arte e promoção da saúde. Rev. Ter. Ocup. Univ. São Paulo, v. 18, n. 3, p. 102-112, 2007. 
COSTA, A. L. B. et al. O programa permanente composições artísticas e terapia ocupacional (PACTO): uma proposta de atenção na interface arte-saúde. Rev. Ter. Ocup. Univ. São Paulo, v. 11, n. 2/3, p. 45-55, 2000.

DA SILVA, T. T. A produção social da identidade e da diferença. In: DA SILVA, T. T. (Ed.). Identidade e Diferença. Rio de Janeiro: Ediotra Vozes, 2000. p. 73-102.

DARDOT, P.; LAVAL, C. A nova razão do mundo: ensaio sobre a sociedade neoliberal. São Paulo: Boitempo, 2016.

DUARTE, L. F. D. et al. Vicissitudes E Limites Da Conversão À Cidadania Nas Classes Populares Brasileiras. Revista Brasileira de Ciências Sociais, v. 8, n. 22, p. 5-19, 1993.

FABBRINI, R. N. Arte relacional e regime estético: a cultura da atividade dos anos 1990. Revista Científica/FAP (Curitiba), v. 5, p. 11-24, 2010.

FOSTER, H. O artista enquanto etnográfo. Arte \& Ensaios, n. 12, p. 36-51, 2005.

FOUCAULT, M. [1979] Microfísica do Poder. 4. ed. Rio de Janeiro: Edições Graal, 1995.

FOUCAULT, M. História da Sexualidade I: A vontade de saber. 12. ed. Rio de Janeiro: Edições Graal, 1997.

FOUCAULT, M. Michel Foucault, uma entrevista: sexo, poder e a política da identidade. Verve, p. 260-277, 2004.

HARDT, M.; NEGRI, A. Multidão: guerra e democracia na era do Império. Rio de Janeiro: Record, 2005.

HÖFLING, E. D. M. Estado e políticas (públicas) sociais. Cadernos CEDES, v. 21, n. 55, p. $30-41,2001$.

LIMA, E. M. F. A. Desejando a diferença: considerações acerca das relações entre os terapeutas ocupacionais e as populações tradicionalmente atendidas por estes profissionais. Revista de Terapia Ocupacional da Universidade de São Paulo, v. 14, n. 2, p. 64-71, 2003.

LIMA, E. M. F. A. et al. Ação e criação na interface das artes e da saúde. Rev. Ter. Ocup. Univ. São Paulo, 2009.

NANCY, J.-L. La communauté desoeuvrée. Paris: Christian Bougois, 1986.

NANCY, J.-L. La communauté affrontée. Paris: Galilée, 2001.

PÈLBART, P. P. Elementos para uma cartografia da grupalidade. Próximo ato: questões da teatralidade contemporânea, p. 1-10, 2008.

RANCIÈRE, J. Sobre políticas estéticas. Barcelona: Museu d'Art Contemporani de Barcelona y Servei de Publicacions de la Universitat Autônoma de Barcelona, 2005. 
RANCIÈRE, J. O espectador emancipado. São Paulo: Editora WMF Martins Fontes, 2012.

RIBEIRO, A. P. Práticas artísticas e comunidades heterogéneas. In: CRUZ, H. A. (Ed.). . Arte e Comunidade. Porto: Fundação Calouste Gulbenkian, 2015. p. 6-7.

SPIVAK, G. C. Pode o subalterno falar? Belo Horizonte: Editora UFMG, 2010.

VALENT, I. U.; CASTRO, E. D. Por entre as linhas dos dispositivos: desafios das práticas contemporâneas na interface terapia ocupacional e cultura. Cadernos de Terapia Ocupacional da UFSCAR. São Carlos, v. 24, n. 4, p. 837-848, 2016. 